\title{
In honor of Professor Alfredo Sanz-Medel
}

\author{
José Luis Pérez-Pavón ${ }^{1}$ • Elena Dominguez Cañas ${ }^{2}$ \\ Published online: 21 February 2019 \\ (C) Springer-Verlag GmbH Germany, part of Springer Nature 2019
}

Prof. Alfredo Sanz Medel was an editor of Analytical \& Bioanalytical Chemistry (ABC) until the end of December 2018. As one of the founding editors and after almost 18 years, it is a pleasure for the previous and current Presidents of the Spanish Society of Analytical Chemistry (Sociedad Española de Química Analítica (SEQA)) to acknowledge his dedication by writing this editorial.

Alfredo obtained his Ph.D. in chemistry from the University of Zaragoza in 1973. After a postdoctoral stay at Imperial College in London, he moved to the Complutense University in Madrid and later, in 1978, to the University of Oviedo, where he became a professor of Analytical Chemistry in 1982. After more than 50 years of teaching and research, the University of Oviedo has acknowledged his extensive scientific background with his nomination as Emeritus Professor.

As representatives of the Spanish analytical community, we want to highlight three aspects of Alfredo's extensive professional career. First, his academic career itself, which is characterized by hard and fruitful work with complete loyalty to the university. His dedication as an editor of $\mathrm{ABC}$ is also instilled with intense and accurate work that has translated into our community ranking as one of the top contributors to $\mathrm{ABC}$. Third, and extremely relevant for us, Alfredo has always been and remains a reference, a guide, and a permanent source of advice for our community, with a rather unique and wise merging of analytical methodology and technical development.

Alfredo's teaching and research career is acknowledged nationally and internationally. He created and led a solid research group for a long time, and he has supervised almost 70

José Luis Pérez-Pavón jlpp@usal.es

1 Department of Analytical Chemistry, University of Salamanca, Plaza de la Merced S/N, 37008 Salamanca, Spain

2 Faculty of Pharmacy/Department of Analytical Chemistry, University of Alcalá de Henares, 28871 Madrid, Spain
Ph.D. theses. His scientific outcome is outstanding, and he is an author or coauthor of more than 600 articles in international journals, several patents, and books. More than this, the main characteristic of his work is novelty and the opening of research lines to solve difficult analytical problems through a multidisciplinary approach.

His main research lines were related to analytical spectroscopy, and some of the most representative examples are as follows:

- New atomic detectors and methodologies for ultratrace multi-elemental analysis (GD-OES, GD-MS, ICP-MS)

- Molecular sensors based on luminescent techniques and nanotechnology for environmental and biomedical analysis (RTP, nanoparticles)

- Development of hybrid techniques for the speciation of elements in environmental and biological fields (GC, HPLC, and AF4 coupled to ICP-MS)

- Speciation and proteomics (MS with ICP, MALDI, and ESI sources)

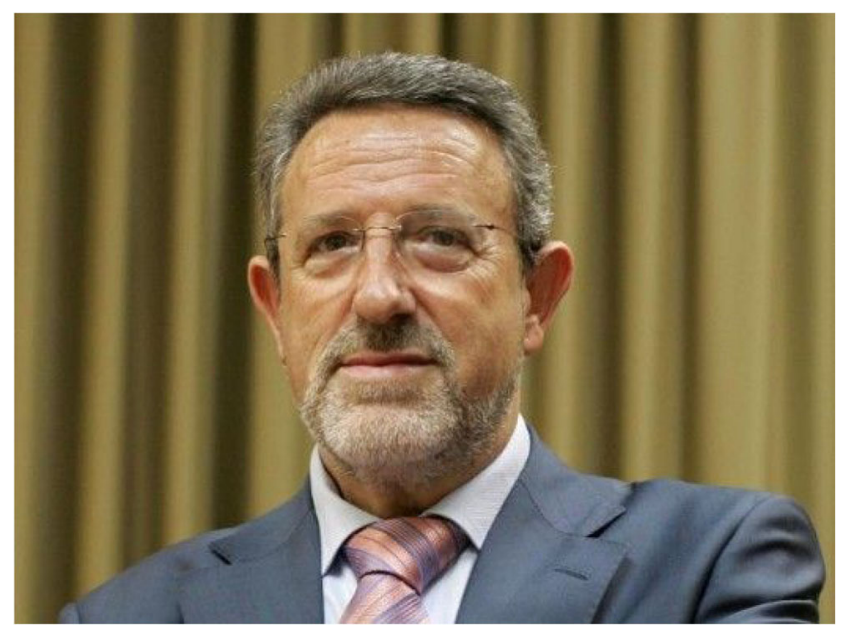

Professor Alfredo Sanz-Medel 
Because of his achievements, Alfredo has been awarded several international prizes, among these are as follows:

- 2007. Robert Kellner Lecture (Antwerp, Belgium)

- 2011. Plasma European Winter Conference Award (Zaragoza, Spain)

- 2011. EuCheMS Lecture Award (Belgrade, Serbia)

- 2015. Colloquium Spectroscopicum Internationale, CSI 2015 Award (Coimbra, Portugal)

In 2017, The Analytical Scientist included Alfredo among the Top 10 spectroscopists due to his "Diverse and extensive contributions to analytical spectrochemical methods" (nominator's comment).

Alfredo has been on the editorial board of the Journal of Analytical Atomic Spectroscopy and Microchimica Acta and a member of the advisory boards of Talanta, Spectrochimica Acta (part B), and Monographs in Analytical Spectroscopy.

Since 2002, he has been an editor of ABC, and the members and board of SEQA have always considered him as "our" representative on the editorial board of the journal. He always invested great efforts to promote the journal among the Spanish analytical community.
Alfredo was President of the Spanish Spectrochemical Group within the Royal Spanish Society of Chemistry (1989-1998)

He has been a member of SEQA since it was created. His cooperation with SEQA has always been full and, as one of the most reputed members or during his time as a member of the board, he always gave priceless advice upon request.

Dear Alfredo, on behalf of SEQA and of all its members, we want to express our gratitude to you for promoting Spanish analytical chemistry and for always being ready to help. You have been an inspiring scientist for the current generation of analytical chemists, and you will be a reference for the future.

Thanks for everything.

Elena Domínguez Cañas

Previous President SEQA

José Luis Pérez Pavón

Current President SEQA

Publisher's note Springer Nature remains neutral with regard to jurisdictional claims in published maps and institutional affiliations. 